\title{
Postpartum meloxicam administration alters plasma haptoglobin, polyunsaturated fatty acid, and oxylipid concentrations in postpartum ewes
}

Katie E. Olagaray ${ }^{1}$, Barry J. Bradford ${ }^{1 *}$ (D) Lorraine M. Sordillo², Jeffery C. Gandy², Laman K. Mamedova ${ }^{1}$, Turner H. Swartz', Trey D. Jackson³, Emma K. Persoon³ ${ }^{3}$ Caitlin S. Shugart ${ }^{3}$ and Curtis R. Youngs ${ }^{3}$

\begin{abstract}
Background: Postpartum inflammation is a natural and necessary response; however, a dysfunctional inflammatory response can be detrimental to animal productivity. The objective of this study was to determine the effects of a non-steroidal anti-inflammatory drug (meloxicam) on ewe postpartum inflammatory response, ewe plasma polyunsaturated fatty acid and oxylipid concentrations, and lamb growth.

Results: After lambing, 36 Hampshire and Hampshire $\times$ Suffolk ewes were sequentially assigned within type of birth to control $(n=17)$ or meloxicam orally administered on d 1 and 4 of lactation (MEL; $90 \mathrm{mg}, n=19$ ). Milk and blood samples were collected on $d 1$ (prior to treatment) and d 4. Milk glucose-6-phosphate was not affected by MEL. Plasma haptoglobin (Hp) concentrations were less for MEL ewes; control ewes with greater d $1 \mathrm{Hp}$ concentrations had elevated $\mathrm{Hp}$ on $\mathrm{d}$ 4, but this was not the case for MEL-treated ewes. Treatment with MEL increased plasma arachidonic acid concentration by more than 4-fold in ewes rearing singles but decreased concentrations of 9,10-dihydroxyoctadecenoic acid, prostaglandin $F_{2 a}$, 8-iso-prostaglandin $E_{2}$, and 8,9dihydroxyeicosatetraenoic acid. Nine oxylipids in plasma had interactions of treatment with d $1 \mathrm{Hp}$ concentration, all of which revealed positive associations between $\mathrm{d} 1 \mathrm{Hp}$ and $\mathrm{d} 4$ oxylipid concentrations for CON, but neutral or negative relationships for MEL. MEL decreased 13-hydroxyoctadecadienoic acid:13-oxooctadecadienoic acid ratio and tended to increase 9-hydroxyoctadecadienoic acid:9-oxooctadecadienoic acid ratio (both dependent on d 1 values), indicating progressive metabolism of linoleic acid-derived oxylipids occurred by enzymatic oxidation after MEL treatment. Meloxicam reduced oxylipids generated across oxygenation pathways, potentially due to an improved redox state.
\end{abstract}

Conclusions: Postpartum MEL treatment of ewes decreased plasma concentrations of Hp and several oxylipids, with the greatest impact in ewes with biomarkers reflecting a greater inflammatory state before treatment. Antiinflammatory strategies may help resolve excessive postpartum inflammation in some dams.

Keywords: Eicosanoid, Inflammation, Lactation, Nonsteroidal anti-inflammatory drug, Sheep

\footnotetext{
* Correspondence: bjbrad@msu.edu

'Department of Animal Sciences and Industry, Kansas State University, Manhattan 66506, USA

Full list of author information is available at the end of the article
}

(c) The Author(s). 2020 Open Access This article is licensed under a Creative Commons Attribution 4.0 International License, which permits use, sharing, adaptation, distribution and reproduction in any medium or format, as long as you give appropriate credit to the original author(s) and the source, provide a link to the Creative Commons licence, and indicate if changes were made. The images or other third party material in this article are included in the article's Creative Commons licence, unless indicated otherwise in a credit line to the material. If material is not included in the article's Creative Commons licence and your intended use is not permitted by statutory regulation or exceeds the permitted use, you will need to obtain permission directly from the copyright holder. To view a copy of this licence, visit http://creativecommons.org/licenses/by/4.0/ The Creative Commons Public Domain Dedication waiver (http://creativecommons.org/publicdomain/zero/1.0/) applies to the data made available in this article, unless otherwise stated in a credit line to the data. 


\section{Background}

Inflammation is a natural and necessary biological response to parturition; however, an uncontrolled inflammatory response can be detrimental to animal productivity. Postpartum inflammation has been well established in dairy cattle [1] with greater degrees of inflammation associated with decreased milk production [2], increased innate immune response [3], and decreased hazard of conception [4]. Use of nonsteroidal anti-inflammatory drugs (NSAID) to attenuate early lactation inflammation has been successful to increase both early lactation $[5,6]$ and whole-lactation milk production [7].

Increased plasma concentrations of the positive acute phase proteins $\alpha 1$-acid glycoprotein, haptoglobin, and ceruloplasmin, suggests sheep also experience postpartum inflammation [8]. To our knowledge, associations of postpartum inflammatory biomarkers with health and productivity of ewes and their lambs have not been evaluated, nor have there been any studies that investigated antiinflammatory intervention strategies in sheep. Meloxicam is non-steroidal anti-inflammatory drug approved for use in Australia, New Zealand, and Canada, but the scope of research has been limited to its analgesic application during events such as lameness [9], castration, tail docking [10], and mulesing [11]. If postpartum meloxicam administration induces responses in ewes similar to those reported in dairy cattle [5-7], there is potential to improve ewe health and increase ewe milk production with subsequent increases in growth of suckling lambs.

Meloxicam decreases inflammation by inhibiting cyclooxygenase-2 (COX-2), the enzyme responsible for converting polyunsaturated fatty acids (PUFA) to oxylipids that include prostaglandins, thromboxanes, and leukotrienes [12]. The inhibitory action of meloxicam on COX-2 is known, but much remains to be elucidated with respect to the mechanism through which meloxicam changes physiology. The few plasma parameters that have been measured ( $\mathrm{Hp}$ and serum amyloid $\mathrm{A}$ ) in response to postpartum meloxicam treatment in cows were unaltered $[7,13,14]$. Despite the direct effect of meloxicam on one of the enzymatic pathways responsible for oxylipid synthesis, to our knowledge investigation of how meloxicam might create shifts within the oxylipid network has been limited to knee synovial fluid in horses [15] and humans [16].

Our primary objective was to determine if postpartum meloxicam administration to ewes would alter biomarkers of systemic inflammation. Our secondary objective was to determine the effect of postpartum meloxicam treatment of ewes on offspring growth. We hypothesized that postpartum meloxicam administration to ewes would reduce biomarkers of systemic inflammation, increase ewe milk production, and lead to greater lamb growth, particularly for ewes rearing twins.

\section{Methods}

Experimental procedures were approved by the Iowa State University Institutional Animal Care and Use Committee (protocol \#5-17-8532-O).

\section{Animals and treatments}

Thirty-six ewes lambing during the 2018 winter lambing season at the Iowa State University Sheep Teaching Farm were used in a randomized design. At lambing ewes were sequentially assigned within type of birth (i.e. singleton, twin) to control (CON; $n=17)$ or treatment with meloxicam (MEL; $n=19$ ). A dose of $90 \mathrm{mg}$ of meloxicam, approximately $1 \mathrm{mg} / \mathrm{kg} \mathrm{BW}$ (six $15 \mathrm{mg}$ tablets in a \#13 veterinary capsule; Torpac Inc., Fairfield, $\mathrm{NJ})$ was administered orally within $24 \mathrm{~h}$ of lambing (d 1 ) and again on $\mathrm{d} 4$ of lactation. Treatment time points were chosen for the first to be the most proximal time to lambing without hindering placenta expulsion [14], and the second to follow $3 \mathrm{~d}$ later, based on the $72 \mathrm{~h}$ clearance rate of meloxicam in sheep $[17,18]$.

Ewes and lambs were housed in a dry lot barn from the time of birth until weaning. Ewes typically lambed in communal lambing pens and were then moved into individual $4^{\prime} \times 5^{\prime}$ postpartum acclimation pens for no more than $48 \mathrm{~h}$. If a lamb was not thriving, the ewe and lamb(s) may have stayed in the individual postpartum pen for up to $96 \mathrm{~h}$. The number of lambs born and reared were recorded. Fewer lambs were reared than born because of lamb death and removal of lamb(s) from ewes with insufficient milk. Descriptive statistics of ewes and lambs pre-treatment are presented in Table 1.

To avoid the potential stress associated with frequent sorting and weighing of lambs at specific $d$ of age, which could adversely impact lamb growth performance, lambs were weighed and weaned in groups. Lambs were weighed at approximately $30 \mathrm{~d}$ of age $(32 \pm 2 \mathrm{~d})$, weaning (61 $\pm 6 \mathrm{~d}$ of age), and approximately 30 and $60 \mathrm{~d}$ postweaning ( $90 \pm 5$ and $120 \pm 6 \mathrm{~d}$ of age, respectively). To reflect potential treatment effects on lamb weight gained per ewe, birth weights were removed, and lamb weights standardized to a constant $d$ of age. For example, 30-d lamb weight gain was calculated by subtracting lamb birth weight from actual lamb weight (near $30 \mathrm{~d}$ of age) and then dividing the resultant value by the lamb's age (in d) to acquire an average daily gain (ADG). The lamb's ADG was then multiplied by 30 to achieve weight gained by $30 \mathrm{~d}$. Because the effect of ewe meloxicam treatment on lamb growth was evaluated as lamb weight gained per ewe, for twin-rearing ewes it represents the combined weight gain of each twin lamb.

\section{Sampling and analysis}

Blood samples were collected from each ewe within $24 \mathrm{~h}$ of lambing (immediately prior to MEL treatment) and 
Table 1 Descriptive statistics for control ewes, ewes treated with 90 mg meloxicam on d 1 and 4 after lambing, and their lambs

\begin{tabular}{|c|c|c|c|c|}
\hline & \multicolumn{2}{|l|}{ Control } & \multicolumn{2}{|l|}{ Meloxicam } \\
\hline & Mean \pm SD & Range & Mean \pm SD & Range \\
\hline \multicolumn{5}{|l|}{ Ewe data } \\
\hline$n$ & 17 & & 19 & \\
\hline \multicolumn{5}{|l|}{ Breed } \\
\hline Hampshire & 12 (71\%) & & 16 (84\%) & \\
\hline Hampshire $\times$ Suffolk & $5(29 \%)$ & & $3(16 \%)$ & \\
\hline Parity & $4.2 \pm 2.2$ & $1-8$ & $3.2 \pm 2.1$ & $1-7$ \\
\hline Weight, kg & $97.5 \pm 15.1$ & $73.5-122.0$ & $90.4 \pm 17.3$ & $64.9-142.4$ \\
\hline Total No. lambs born/trt & 28 & & 33 & \\
\hline Avg. No. lambs born/ewe & $1.65 \pm 0.49$ & $1-2$ & $1.74 \pm 0.56$ & $1-3$ \\
\hline 1 & $6(33 \%)$ & & $6(32 \%)$ & \\
\hline 2 & $11(56 \%)$ & & $12(63 \%)$ & \\
\hline 3 & 0 & & $1(5 \%)$ & \\
\hline Avg. No. lambs reared & $1.59 \pm 0.51$ & $1-2$ & $1.63 \pm 0.50$ & $1-2$ \\
\hline Total No. lambs reared & 27 & & 31 & \\
\hline 1 & $7(41 \%)$ & & $7(37 \%)$ & \\
\hline 2 & 10 (59\%) & & 12 (63\%) & \\
\hline \multicolumn{5}{|l|}{ Sire Breed } \\
\hline Hampshire & 13 (76\%) & & 16 (84\%) & \\
\hline Hampshire $\times$ Suffolk & $4(24 \%)$ & & $3(16 \%)$ & \\
\hline \multicolumn{5}{|l|}{ Lamb data } \\
\hline \multicolumn{5}{|l|}{ Sex of lamb } \\
\hline Male & 16 (59\%) & & $16(48 \%)$ & \\
\hline Female & $11(41 \%)$ & & 15 (52\%) & \\
\hline Birth weight, kg & $6.7 \pm 0.7$ & $5.2-8.4$ & $6.4 \pm 1.0$ & $4.5-8.6$ \\
\hline
\end{tabular}

again 3 d later. Samples were collected into 2 evacuated tubes (Thermo Fisher Scientific Inc. Waltham, MA), one containing heparin and the other $\mathrm{K}_{3}$ EDTA, inverted several times, and placed on ice. Samples were centrifuged at $3000 \times g$ for $15 \mathrm{~min}$ at $20^{\circ} \mathrm{C}$ and plasma transferred to 1.5 $\mathrm{mL}$ microcentrifuge tubes for storage at $-80^{\circ} \mathrm{C}$ until analyses. Prior to storing, plasma from EDTA tubes were snap frozen in liquid nitrogen for PUFA and oxylipid analyses. Milk samples were also collected from ewes on d 1 (to avoid colostrum) and d 4 of lactation. Milk samples were centrifuged at $1380 \times g$ for $20 \mathrm{~min}$ at $4{ }^{\circ} \mathrm{C}$. The fat layer was removed, and skim milk was stored at $-20^{\circ} \mathrm{C}$ until analysis of glucose and glucose-6-phosphate (G6P).

Milk glucose and G6P concentrations were measured by a fluorometric assay as previously described [19, 20]. In short, G6P was determined through enzymatic oxidation by G6P dehydrogenase using $\mathrm{NADP}^{+}$and the total (both glucose and G6P) was determined by enzymatic oxidation by both G6P dehydrogenase and hexokinase. Intra- and inter-assay coefficients of variation for G6P were $2.5 \%$ and $2.3 \%$, and for glucose were $4.1 \%$ and
$3.0 \%$, respectively. Results are presented as both G6P concentration and G6P as a percent of total glucose available for phosphorylation.

Haptoglobin ( $\mathrm{Hp}$ ) was measured using a colorimetric assay that measures $\mathrm{Hp}$-hemoglobin complexing via differences in peroxidase activity [21]. Haptoglobin concentrations from the colorimetric assay were validated using a commercial ELISA kit (cat\#HAPT-11; Life Diagnostics Inc., West Chester, PA). Trolox equivalent antioxidant capacity (TEAC) was measured using a commercial antioxidant assay kit (\#709001; Cayman Chemical; Ann Arbor, MI). Intra- and inter-assay coefficients of variation for haptoglobin were $3.5 \%$ and $4.3 \%$, and for TEAC were $3.0 \%$ and $3.4 \%$, respectively.

Plasma PUFA were analyzed with LC-MS and oxylipids by LC-MS/MS [22]. Briefly, $1 \mathrm{~mL}$ plasma was mixed with an antioxidant reducing agent mixture $(50 \%$ methanol, 25\% ethanol, and 25\% water), butylhydroxytoluene $(0.9 \mathrm{mmol} / \mathrm{L})$, EDTA $(0.54 \mathrm{mmol} / \mathrm{L})$, triphenyphosphine $(3.2 \mathrm{mmol} / \mathrm{L})$, and indomethacin $(5.6 \mathrm{mmol} /$ L) to prevent ex vivo lipid peroxidation and oxidation 
of preformed oxylipids [23]. The following internal standards were added to each sample: 5 (S)-hydroxyeicosatetraenoic acid $-d_{8}(0.25 \mu \mathrm{mol} / \mathrm{L}), 15(\mathrm{~S})$-hydroxyeicosatetraenoic acid- $d_{8} \quad(0.25 \mu \mathrm{mol} / \mathrm{L}), \quad 8,9-$ epoxyeicosatrienoic acid- $d_{11}$ $(0.5 \mu \mathrm{mol} / \mathrm{L})$, prostaglandin $\mathrm{E}_{2}-d_{9}(0.5 \mu \mathrm{mol} / \mathrm{L}), 8$,9-dihydroxyeicosatrienoic acid- $d_{11}(0.25 \mu \mathrm{mol} / \mathrm{L})$, arachidonic acid- $d_{8}$ $(50 \mu \mathrm{mol} / \mathrm{L}), 2$-arachidonoyl glycerol- $d_{8}(2 \mu \mathrm{mol} / \mathrm{L})$, and arachidonoyl ethanolamide- $d_{8}(0.25 \mu \mathrm{mol} / \mathrm{L})$ in $15 \mu \mathrm{L}$. A 7-point standard curve was generated with a mix of standards and internal standards for quantification.

Solid phase extraction was used for both PUFA and oxylipids [22]. Samples were reconstituted in a 2:1 methanol: HPLC-grade water mixture and passed through Acrodisc 13 mm GHP $0.2 \mu \mathrm{m}$ syringe filters (Waters, Milford, MA) to remove any particulates. Samples were transferred to glass chromatography vials with glass inserts.

Fatty acids were quantified using a reverse phase LC on a Waters Acquity UPLC with a Supleco (State College, PA) Ascentis Express C18 $10 \mathrm{~cm} \times 2.1 \mathrm{~mm}, 2.7 \mu \mathrm{m}$ column with a flow rate of $0.35 \mathrm{~mL} / \mathrm{min}$ at $50{ }^{\circ} \mathrm{C}$ coupled to a quadrupole mass spectrometer. Mobile phases included $\mathrm{A}=$ acetonitrile, $\mathrm{B}=$ methanol, and $\mathrm{D}=0.1 \%$ for mic acid. The gradient mobile phase was programmed as follows (A/B/D ratio): time 0 to $0.2 \mathrm{~min}(45 / 22 / 33)$, to $(80 / 19 / 1)$ at $4.0 \mathrm{~min}$ and maintained to $5.0 \mathrm{~min}$, to $(45 /$ 22/33) at $6 \mathrm{~min}$ and held until $8 \mathrm{~min}$. Fatty acids were identified and quantified by matching mass- 1 and retention time with corresponding internal standard and calibrated using a linear 7-point standard curve $\left(R^{2}>0.99\right)$.

Oxylipids were quantified using a Waters Acquity UPLC connected to a Waters Xevo-TQ-S tandem quadrupole mass spectrometer using multiple reaction monitoring. The Ascentis Express C18 HPLC column (Sigma Aldrich) was set at $50^{\circ} \mathrm{C}$ and the autosampler at $10^{\circ} \mathrm{C}$. Flow rate was $0.3 \mathrm{~mL} / \mathrm{min}$. Eluents included $0.1 \%$ formic acid in water (A) and acetonitrile (B). The $15 \mathrm{~min}$ run time was programmed with a linear gradient as follows (A:B ratio): time 0 to $0.5 \mathrm{~min}(99: 1)$, to $(60: 40)$ at 2.0 $\mathrm{min}$, to $(20: 80)$ at $8.0 \mathrm{~min}$, to $(1: 99)$ until $13.0 \mathrm{~min}$, then returned to (99:1) at $13.01 \mathrm{~min}$, and held until $15.0 \mathrm{~min}$. Oxylipids were detected using electrospray ionization in negative-ion mode. Cone voltage and collision voltages were optimized for each analyte using Waters QuanOptimize software [23], and data analysis was carried out with Waters TargetLynx software.

All samples for fatty acid and oxylipids were analyzed in one batch. The signal to noise ratio was monitored; only data with a signal to noise ratio above 3 were considered detected and data with a signal to noise ratio $\geq$ 10 were used for calculations.

\section{Statistical analysis}

Ewe plasma data ( $\mathrm{d}$ 4) were analyzed using the MIXED procedure of SAS (version 9.4, SAS Institute, Cary, NC) with the fixed effects of treatment, d 1 covariate values, number of lambs born, and the two-way interactions of these variables, the quadratic term for $d 1$ covariate values and its interaction with treatment, the $\mathrm{d} 1$ covariate for $\mathrm{Hp}$, and the Hp covariate $\times$ treatment interaction. Ewe was included as a random effect. Treatment and covariates for outcomes of interest were retained in all models. Unless part of a significant interaction, all other variables were removed from the model when $P>0.20$. Residual plots were assessed visually for normality. Any parameters violating that assumption were log-transformed prior to analysis with reported data back-transformed.

Weight of lamb raised per ewe at approximately 30 , 60,90 , and $120 \mathrm{~d}$ of lamb age was analyzed using the MIXED procedure of SAS (version 9.4, SAS Institute, Cary, NC) with the fixed effects of treatment, number of lambs reared, lamb sex, and their two-way interactions, and with the random effect of ewe. Variables were removed from the model when $P>0.20$.

All models utilized variance components as the covariance structure and removed observations when Studentized residuals were $\leq-3$ or $\geq 3$. Significance was declared at $P<0.05$ and tendencies at $0.05 \leq P<0.10$.

\section{Results \\ Ewe inflammatory, oxidative balance, and energy balance biomarkers}

Plasma Hp concentrations were lesser for MEL ewes, indicating reduced inflammatory status of ewes $(P<0.05)$; however, magnitude of the treatment response was dependent on d $1 \mathrm{Hp}$ concentrations ( $P=0.04$; Fig. 1$)$. As expected, there was a positive relationship between $\mathrm{d}$ 1 and $\mathrm{d} 4 \mathrm{Hp}$ concentrations in control ewes, but meloxicam treatment eliminated this association. Ewes treated with MEL had similar d $4 \mathrm{Hp}$ concentrations regardless of pre-treatment (d 1) concentration. Plasma TEAC, a measure of antioxidant capacity, did not differ between control and MEL ewes $(P=0.82)$. Milk G6P, an indirect indicator of ewe energy balance, was unaltered by MEL whether expressed as a concentration or as a percent of milk glucose $(P \geq 0.12$; Table 2$)$.

\section{Ewe plasma polyunsaturated fatty acid concentrations}

Quantified plasma PUFA included linoleic acid (LA), arachidonic acid (ArA), eicosapentaenoic acid, dihomolinolenic acid, adrenic acid, and docosahexaenoic acid (Table 3). Among PUFA, ArA was the only one altered by MEL, with concentrations increased by more than 4fold in ewes rearing singles $(P<0.01$ main effect and interaction; Fig. 2).

\section{Ewe oxylipid profile}

Plasma samples were analyzed for 57 oxylipids, 36 of which were detected and 31 of which were statistically 


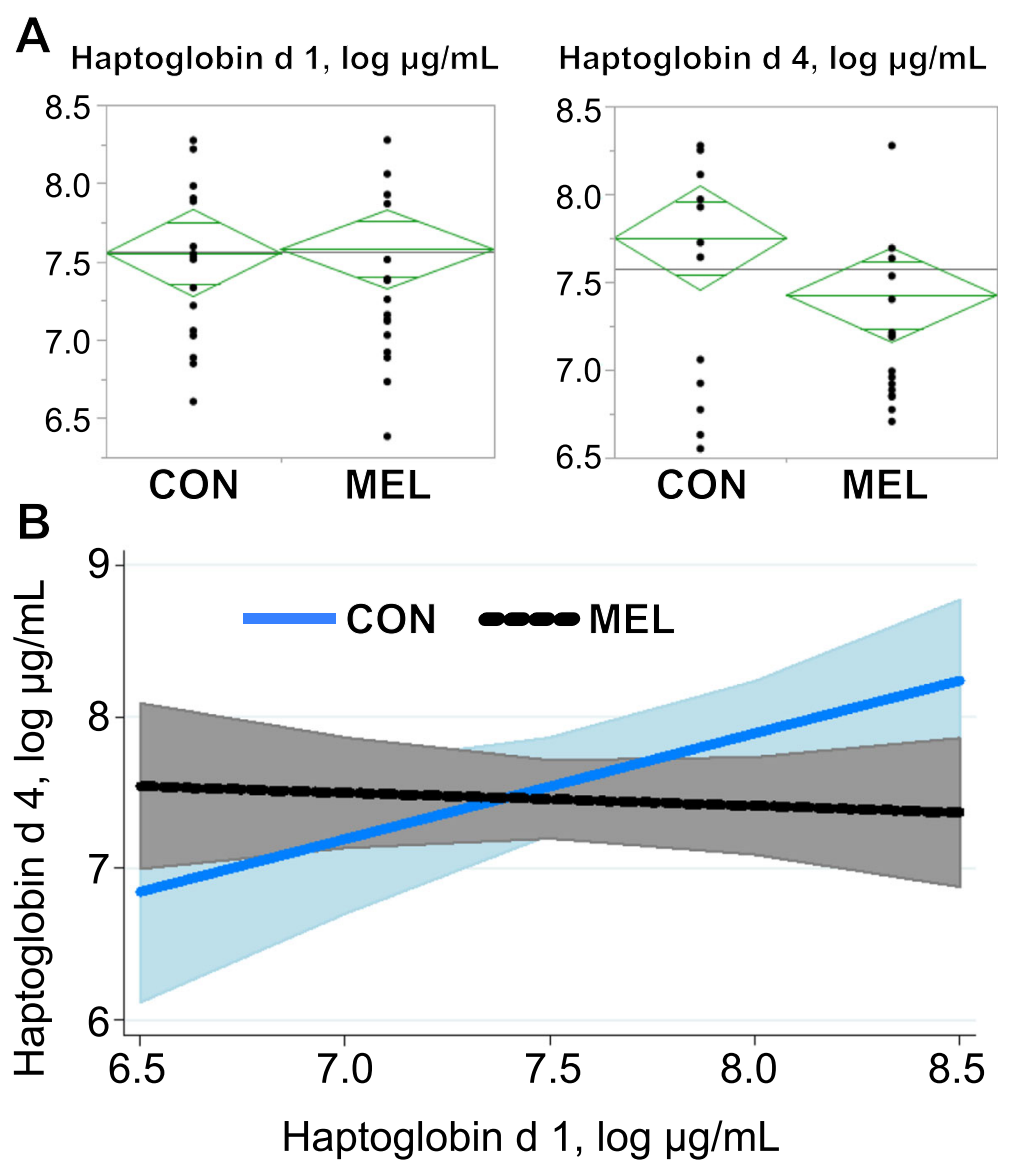

Fig. 1 Baseline (d 1) haptoglobin relationship with d 4 haptoglobin is altered by meloxicam. a Log-transformed haptoglobin concentrations on d 1 (prior to treatment) and d 4 of lactation. The diamonds show means and 95\% confidence intervals of the mean for each group. $\mathbf{b}$ Log haptoglobin concentration $\times$ treatment interaction $(P=0.04)$. Control ewes that had greater plasma haptoglobin concentration on $\mathrm{d} 1$ had greater haptoglobin concentration on $d 4$, whereas initial plasma haptoglobin concentration on d 1 (before meloxicam) of treated ewes was not related to their $d 4$ values. D 4 haptoglobin concentration $(\log )=8.10-0.09 \times \log$ haptoglobin covariate $-5.8[$ control] $+0.78 \times \log$ haptoglobin covariate[control]. Shaded areas represent $95 \%$ confidence intervals

Table 2 Plasma biomarkers of inflammation (haptoglobin) and antioxidant capacity (TEAC) and milk markers of energy balance (G6P) in ewes treated with meloxicam at $d 1$ and 4 after lambing

\begin{tabular}{|c|c|c|c|c|c|c|}
\hline & \multirow[b]{2}{*}{ CON } & \multirow[b]{2}{*}{ MEL } & \multirow[b]{2}{*}{ SEM } & \multicolumn{3}{|c|}{$P$-values ${ }^{1}$} \\
\hline & & & & Trt & Cov & $\operatorname{Cov} \times \operatorname{trt}$ \\
\hline \multicolumn{7}{|l|}{ Plasma } \\
\hline Haptoglobin, $\mu \mathrm{g} / \mathrm{mL}$ & 2063 & 1713 & 275 & $<0.05$ & NS & 0.04 \\
\hline TEAC, mmol/L & 1.00 & 1.00 & 0.02 & NS & NS & NS \\
\hline \multicolumn{7}{|l|}{ Milk } \\
\hline $\mathrm{G} 6 \mathrm{P}^{2}, \mu \mathrm{mol} / \mathrm{L}$ & 190.4 & 218.0 & 13.8 & NS & 0.01 & 0.09 \\
\hline $\mathrm{G} 6 \mathrm{P}^{3}, \%$ of glucose & 76.2 & 82.6 & 2.80 & NS & NS & NS \\
\hline
\end{tabular}

${ }^{1} \mathrm{NS}: P>0.10$; Cov: effect of $\mathrm{d} 1$ covariate

${ }^{2} \operatorname{Cov} \times \operatorname{cov}: P=0.01 ; \operatorname{Cov} \times \operatorname{cov} \times \operatorname{trt}: P=0.08$

${ }^{3}$ Effect of haptoglobin covariate: $P=0.05$ analyzed. Although detectable, concentrations of $\mathrm{PGD}_{2}, 11$, 12- epoxy-eicosatrienoic acid (EET), 14,15-EET, 6-ketoprostaglandin (PG) $\mathrm{F}_{1 \alpha}$, and 10,17- dihydroxydocosahexaenoic acid were very low and lacked sufficient variation to detect treatment differences. Effects of MEL on oxylipids are summarized by biosynthetic pathway (COX, lipoxygenase [LOX], cytochrome P450 [CYP], and non-enzymatic oxidation [NE]) in Tables 4, 5, 6, 7 and 8 . Overall shifts to the oxylipid network can be visualized in Fig. 3 .

The interaction between treatment and initial $\mathrm{Hp}$ concentration (Fig. 4) was significant or tended to be significant for many oxylipids (12- hydroxyeicosatrienoic acid [HHTrE], 11-hydroxyeicosatetraenoic acid [HETE], 9-hydroxyoctadecadienoic acid [HODE], 9-oxooctadecadienoic acid [oxoODE], 15-HETE, 9, 10-epoxyoctadecenoic acid [EpOME], 20-HETE, 14, 15-dihydroxyeicosatrienoic acid [DHET], and 9-HETE: $P<0.05 ; 8,9$-DHET and 19,20- dihydroxydocosapentaenoic acid [DiHDPA]: $P<0.10$ ). Generally, the 
Table 3 Plasma polyunsaturated fatty acid concentrations $(\mu \mathrm{mol} / \mathrm{L})$ in control ewes and ewes treated with 90 mg meloxicam on d 1 and 4 after lambing

\begin{tabular}{|c|c|c|c|c|c|c|c|}
\hline \multirow{2}{*}{ Fatty acid } & & \multirow[b]{2}{*}{ CON } & \multirow[b]{2}{*}{ MEL } & \multirow[b]{2}{*}{ SEM } & \multicolumn{3}{|c|}{$P$-values ${ }^{1}$} \\
\hline & & & & & $\overline{T r t}$ & Cov & $\overline{\text { Lambs }}$ \\
\hline Linoleic acid $^{2}$ & C18:2 (n-6) & 97.61 & 86.50 & 16.07 & NS & $<0.05$ & $<0.01$ \\
\hline a-linolenic acid & C18:3 (n-3) & 60.50 & 61.20 & 14.27 & 0.16 & NS & $<0.01$ \\
\hline Arachidonic acid ${ }^{3}$ & $C 20: 4(n-6)$ & 4.81 & 10.15 & 1.66 & $<0.01$ & 0.01 & $<0.01$ \\
\hline Eicosapentaenoic acid & $C 20: 5(n-3)$ & 1.13 & 0.94 & 0.20 & NS & NS & 0.06 \\
\hline Dihomo-linolenic acid & $C 20: 6(n-6)$ & 0.33 & 2.22 & 0.34 & NS & 0.03 & NS \\
\hline Adrenic acid & C22:4 & 0.016 & 0.013 & 0.002 & NS & 0.09 & NS \\
\hline Docosahexaenoic acid & $C 22: 6(n-3)$ & 4.11 & 3.55 & 0.70 & 0.15 & 0.11 & 0.02 \\
\hline Total & & 263.6 & 289.6 & 40.4 & NS & NS & $<0.01$ \\
\hline
\end{tabular}

${ }^{1}$ NS: $P>0.20$; Cov: effect of $d 1$ covariate

${ }^{2}$ loghaptocov $\times$ trt: $P=0.03$

${ }^{3} \operatorname{cov} \times \operatorname{trt}: P=0.01 ; \operatorname{cov} \times \operatorname{cov}: P=0.04 ; \operatorname{cov} \times \operatorname{cov} \times \operatorname{trt}: P=0.01 ; \operatorname{trt} \times$ lambs: $P<0.01 ;$ loghaptocov: $P<0.05 ;$ loghaptocov $\times$ trt: $P<0.01$

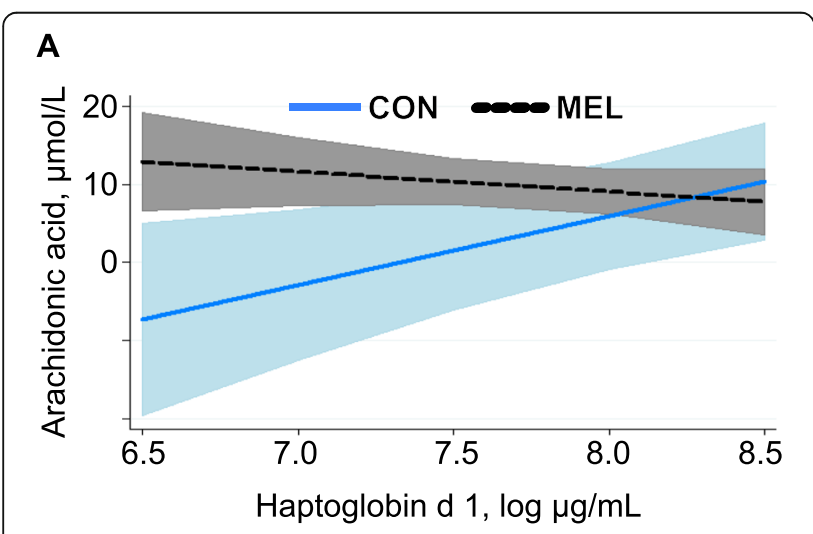

B

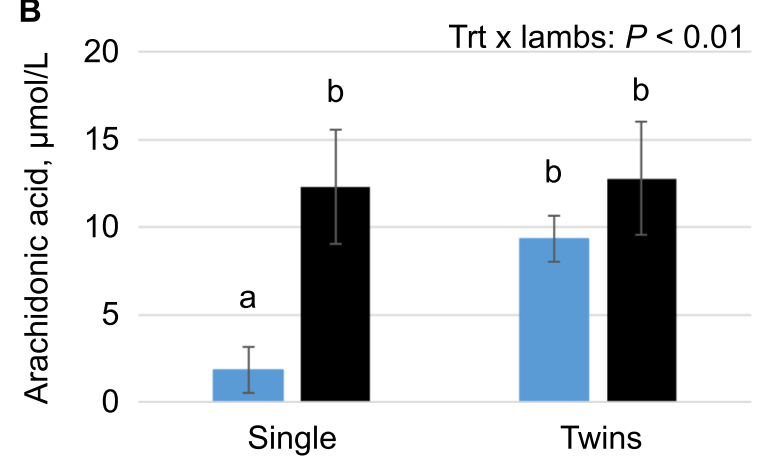

Fig. 2 Meloxicam alters arachidonic acid relationships with baseline haptoglobin and type of rearing. a The treatment $\times$ haptoglobin covariate interaction $(P=0.01)$ for plasma arachidonic acid (ArA) concentration in control ewes (CON) and ewes treated with $90 \mathrm{mg}$ meloxicam (MEL) on $d 1$ and 4 after lambing. D 4 ArA

concentrations was dependent on d 1 haptoglobin concentrations (inflammation marker), with greater initial haptoglobin related to greater ArA in control ewes, but lesser ArA in ewes receiving MEL. D 4 ArA $=7.02-3.87 \times$ covariate $+0.70 \times$ covariate $^{2}-5.41$ [control] + $3.85 \times$ covariate[control] $-0.77 \times$ covariate $^{2}$ [control]. Shaded areas represent $95 \%$ confidence intervals; slopes differ at $P=0.01$. b D 4 plasma ArA was less in control ewes rearing single lambs compared to MEL ewes rearing either single lambs or twins and control ewes rearing twins (Trt $\times$ lambs: $P<0.001)$ observed interactions indicated a positive association between initial inflammatory status and the oxylipid in control ewes, but a negative relationship for MEL ewes.

The detected COX-derived oxylipids were all metabolites of ArA (Table 4). The only main effect of MEL on COX-derived oxylipids was decreased $\mathrm{PGF}_{2 \alpha}$.

The LOX-derived oxylipid concentrations are shown in Table 5. The $\alpha$-linolenic acid metabolite 13-hydroxyocctadecatrienoic acid (HOTrE) tended to have a covariate $\times$ treatment interaction, with greater $\mathrm{d}$ 1 values related to decreased concentrations on $\mathrm{d} 4$ for control, but little difference for MEL $(P=0.08)$. Ewes rearing twins had greater concentrations of 9-HODE (39.9 vs. $57.4 \pm 4.8 \mu \mathrm{mol} / \mathrm{L} ; P=0.03)$, 9-oxoODE (10.7 vs. $16.2 \pm 1.3 \mu \mathrm{mol} / \mathrm{L})$, and 5-HETE $(-0.12$ vs. $0.51 \pm$ $0.23 \mu \mathrm{mol} / \mathrm{L}$ ) compared with ewes rearing singletons. Concentration of 17- hydroxyl-docosahexaenoic acid $(\mathrm{HDoHE})$ tended to have a treatment $\times$ lamb interaction with MEL attenuating the drop in HDoHE otherwise seen in twin-bearing ewes (MEL: 1.03 vs. $0.96 \pm$ $0.29 \mu \mathrm{mol} / \mathrm{L}, \mathrm{CON}: 1.92$ vs. $0.66 \pm 0.33 \mu \mathrm{mol} / \mathrm{L} ; P=0.07$ ).

Effects of MEL on CYP-derived oxylipids are show in Table 6. Treatment with MEL tended to decrease 17,18dihyroxy-eicosatetraenoic acid (DiHETE; $P=0.07$ ). Concentrations of 9,10-DiHOME decreased with MEL, with the largest effect in ewes with greater initial concentrations $(P=0.03)$. MEL also decreased the ArA metabolite 8,9-DHET, and the $\operatorname{cov}^{2} \times$ treatment interaction showed MEL prevented the decrease in $\mathrm{d} 4$ concentrations for ewes with greater initial concentrations of 8,9-DHET $(P=0.05)$. Ewes raising twins had greater concentrations of 9,10-dihydroxyoctadecenoic acid (DiHOME; 18.0 vs. $21.7 \pm 1.1 \mu \mathrm{mol} / \mathrm{L}$ ), 8,9-DHET (0.66 vs. $0.81 \pm 0.18 \mu \mathrm{mol} /$ L), 17,18-DiHETE (36.5 vs. $47.8 \pm 2.5 \mu \mathrm{mol} / \mathrm{L}$ ), and 19 , 20-DiHDPA (1.83 vs. $2.96 \pm 0.24 \mu \mathrm{mol} / \mathrm{L}$; all $P \leq 0.04)$, and a tendency for greater concentrations of 14,15DHET and 14,15-DiHETE (2.34 vs. $2.85 \pm 0.16 \mu \mathrm{mol} / \mathrm{L}$ 
Table 4 Cyclooxygenase-derived oxylipids in plasma in control ewes and ewes treated with 90 mg meloxicam on d 1 and 4 after lambing (mean \pm SEM; $\mu \mathrm{mol} / \mathrm{L})$

\begin{tabular}{|c|c|c|c|c|c|c|c|c|}
\hline \multirow[b]{2}{*}{ Oxylipid $^{2}$} & \multirow[b]{2}{*}{ Substrate $^{3}$} & \multirow[b]{2}{*}{ CON } & \multirow[b]{2}{*}{ MEL } & \multirow[b]{2}{*}{ SEM } & \multicolumn{4}{|c|}{$P$-values ${ }^{1}$} \\
\hline & & & & & Trt & Cov & $\operatorname{Cov} \times \operatorname{cov}$ & $\mathrm{Hpcov} \times \mathrm{trt}$ \\
\hline $\mathrm{PGE}_{2}$ & ArA & 0.19 & 0.15 & 0.03 & NS & 0.10 & NS & NS \\
\hline $\mathrm{PGF}_{2 a}$ & ArA & 0.21 & 0.09 & 0.03 & $<0.01$ & $<0.01$ & $<0.01$ & 0.10 \\
\hline 12-HHTrE & ArA & 0.79 & 0.98 & 0.11 & NS & NS & NS & 0.04 \\
\hline $\mathrm{TXB}_{2}$ & ArA & 1.67 & 2.12 & 0.78 & NS & NS & NS & NS \\
\hline
\end{tabular}

${ }^{1} \mathrm{NS}: P>0.10 ; \mathrm{Cov}=\mathrm{d} 1$ covariate values

${ }^{2} P G$ Prostaglandin, HHTrE Hydroxyeicosatrienoic acid, $T X B_{2}$ Thromboxane $B_{2}$ ${ }^{3}$ ArA Arachidonic acid

and 4.78 vs. $5.92 \pm 0.40 \mu \mathrm{mol} / \mathrm{L}$, respectively; $P=0.07$ ) compared to ewes rearing a single lamb.

MEL effects on oxylipids formed through NE oxidation were mostly dependent on number of offspring reared and initial inflammatory status (Table 7). Concentrations of 8iso- $\mathrm{PGE}_{2}$ were similar amongst control ewes raising singles, control ewes raising twins, and MEL ewes raising twins (0.51, 0.97 , and $0.48 \pm 1.5 \mu \mathrm{mol} / \mathrm{L}$, respectively), but lesser for MEL ewes raising singles $(0.06 \pm 1.4 \mu \mathrm{mol} / \mathrm{L})$. Control ewes with twins had the least 8-iso- $\mathrm{PGA}_{2}$ concentration $(0.28 \pm 0.07 \mu \mathrm{mol} / \mathrm{L})$, control and MEL ewes with singles were intermediate $(0.49$ and $0.41 \pm 0.09 \mu \mathrm{mol} / \mathrm{L})$, and MEL ewes with twins were the greatest $(0.52 \pm 0.07 \mu \mathrm{mol} / \mathrm{L})$. Treatment effects on 9-HETE were influenced by covariate values, in which 9-HETE decreased from initial values for control, but remained greater at $\mathrm{d} 4$ for those treated with $\operatorname{MEL}(P=0.04$; Fig. 4h).

The oxidized LA metabolites 9- and 13-HODE can be formed from COX, LOX, CYP, or non-enzymatic (prooxidant) pathways; however, because racemic structures of these metabolites were not analyzed, we could not determine the relative proportion produced by each oxidation pathway. Treatment effects on 13-HODE and 9HODE depended or tended to depend on $\mathrm{d} 1$ covariate values $(P<0.01$ and $P=0.07)$. Greater 13 -HODE concentrations were positively related to $\mathrm{d} 4$ concentrations for control, but negatively associated for MEL. Concentrations of 9-HODE were greater for MEL, and again there was a positive relationship between $\mathrm{d} 1$ and 4 values in control ewes; however, post-treatment concentrations in MEL were independent of $\mathrm{d} 1$ covariate values (cov $\times \operatorname{trt}: P<0.01)$.

Differences in the progressive metabolism of oxylipids within certain pathways were assessed through ratios of hydroxyl oxylipids to their ketone derivatives (HODE to oxoODE) and epoxides to vicinal diols (EpOME to DiHOME). Ratios of 9-HODE:9-oxoODE and 13-HODE:13oxoODE were both greater than 1 for both control and MEL, which signifies greater abundance of the hydroxyl oxylipids relative to their ketone derivatives. Initial 9-HODE:9oxoODE tended to be positively related to values on $\mathrm{d} 4$ for MEL but negatively related for control $(P=0.06$; Fig. $5 \mathrm{a})$. This ratio also tended to be related to initial inflammatory status with greater initial $\mathrm{Hp}$ related to slight increases for MEL and decreases for control $(P \leq 0.10)$. In contrast, the 13-HODE:13oxoODE ratio was less with MEL, with initial values positively related to $\mathrm{d} 4$ values in control but negatively related in MEL ( $P=0.04$; Fig. $5 b)$. Progressive metabolism of 9,10-EpOME tended to be lesser for MEL $(P=0.06)$; however, unlike the HODE:OxoODE ratios, there was a greater proportion of the downstream metabolite 9,10DiHOME (ratio < 1$)$.

Table 5 Lipoxygenase-derived oxylipids in plasma of control ewes and ewes treated with 90 mg meloxicam on d 1 and 4 after lambing (mean \pm SEM; $\mu \mathrm{mol} / \mathrm{L}$ )

\begin{tabular}{|c|c|c|c|c|c|c|c|c|c|}
\hline \multirow[b]{2}{*}{ Oxylipid $^{2}$} & \multirow[b]{2}{*}{ Substrate $^{3}$} & \multirow[b]{2}{*}{ CON } & \multirow[b]{2}{*}{ MEL } & \multirow[b]{2}{*}{ SEM } & \multicolumn{5}{|c|}{$P$-values ${ }^{1}$} \\
\hline & & & & & $\overline{T r t}$ & Cov & $\operatorname{Cov} \times$ trt & Lambs & $\mathrm{Hpcov} \times \mathrm{trt}$ \\
\hline 5-HETE & $\operatorname{ArA}$ & 0.10 & 0.29 & 0.22 & NS & NS & NS & 0.07 & NS \\
\hline 15-HETE & ArA & 2.03 & 1.96 & 0.16 & NS & 0.02 & NS & NS & 0.02 \\
\hline $5,6-\mathrm{LXA}_{4}$ & $\operatorname{ArA}$ & 0.13 & 0.16 & 0.03 & NS & NS & NS & NS & NS \\
\hline $13(\mathrm{~S})-\mathrm{HOTrE}{ }^{4}$ & ALA & 130.8 & 100.3 & 28.3 & NS & 0.08 & 0.08 & NS & NS \\
\hline $17-\mathrm{HDoHE}^{5}$ & DHA & 1.29 & 0.99 & 0.22 & NS & $<0.01$ & NS & $<0.05$ & NS \\
\hline $\mathrm{RvD}_{2}$ & DHA & 0.30 & 0.17 & 0.06 & NS & NS & NS & NS & NS \\
\hline
\end{tabular}

${ }^{1} \mathrm{NS}=P>0.10 ; \mathrm{Cov}=\mathrm{d} 1$ covariate values

${ }^{2}$ HETE Hydroxyeicosatetraenoic acid, $L X A_{4}$ Lipoxin $\mathrm{A}_{4}, H O T r E$ Hydroxyoctadecatrienoic acid, HDoHE Hydroxyl-docosahexaenoic acid, RvD 2 Resolvin $\mathrm{D}_{2}$

${ }^{3}$ ArA Arachidonic acid, ALA a-Linolenic acid, DHA Docosahexaenoic acid

${ }^{4} \operatorname{Cov} \times \operatorname{cov}: P=0.08$; $\operatorname{cov} \times \operatorname{cov} \times \operatorname{trt}: P=0.08$

${ }^{5} \mathrm{Cov} \times$ cov: $P=0.02 ;$ trt $\times$ lambs: $P=0.07$ 
Table 6 Cytochrome P450-derived oxylipids in plasma in control ewes and ewes treated with 90 mg meloxicam on d 1 and 4 after lambing (mean \pm SEM; $\mu \mathrm{mol} / \mathrm{L})$

\begin{tabular}{|c|c|c|c|c|c|c|c|c|c|c|}
\hline \multirow[b]{2}{*}{ Oxylipid $^{2}$} & \multirow[b]{2}{*}{ Substrate $^{3}$} & \multirow[b]{2}{*}{ CON } & \multirow[b]{2}{*}{ MEL } & \multirow[b]{2}{*}{ SEM } & \multicolumn{6}{|c|}{$P$-values ${ }^{1}$} \\
\hline & & & & & $\overline{T r t}$ & Cov & $\operatorname{Cov} \times \operatorname{cov}$ & Cov $\times$ trt & Lambs & $\overline{H p c o v} \times$ trt \\
\hline 9,10-ЕрОМЕ & LA & 8.20 & 8.12 & 0.52 & NS & $<0.01$ & NS & NS & NS & 0.03 \\
\hline 9,10-DiHOME & LA & 22.13 & 17.55 & 1.05 & $<0.01$ & $<0.10$ & NS & 0.03 & 0.02 & NS \\
\hline 12,13-ЕрОМЕ & LA & 24.30 & 24.09 & 1.68 & NS & - & - & - & - & - \\
\hline 20-HETE & ArA & 5.15 & 5.26 & 0.48 & NS & NS & NS & NS & NS & 0.04 \\
\hline 8,9-DHET ${ }^{4}$ & ArA & 1.11 & 0.36 & 0.19 & 0.04 & 0.10 & 0.04 & NS & 0.04 & 0.07 \\
\hline 11,12-DHET & $\operatorname{ArA}$ & 1.48 & 1.48 & 0.13 & NS & 0.10 & NS & NS & NS & NS \\
\hline 14,15-DHET & $\operatorname{ArA}$ & 2.72 & 2.47 & 0.15 & NS & $<0.001$ & $<0.01$ & NS & 0.07 & 0.03 \\
\hline 14,15-DiHETE & EPA & 5.64 & 5.06 & 0.38 & NS & $<0.01$ & $<0.01$ & 0.10 & 0.07 & NS \\
\hline 17,18-DiHETE & EPA & 45.16 & 39.07 & 2.35 & 0.07 & $<0.001$ & $<0.001$ & NS & $<0.01$ & NS \\
\hline 19,20-EpDPE & $\mathrm{DHA}$ & 3.29 & 4.06 & 0.51 & NS & NS & - & - & - & - \\
\hline 19,20-DiHDPA & $\mathrm{DHA}$ & 2.31 & 2.47 & 2.39 & NS & $<0.01$ & 0.02 & NS & $<0.01$ & 0.09 \\
\hline
\end{tabular}

${ }^{1} \mathrm{NS}=P>0.10 ; \mathrm{Cov}=\mathrm{d} 1$ covariate values

${ }^{2}$ EPOME Epoxyoctadecenoic acid, DiHOME Dihydroxyoctadecenoic acid, HETE Hydroxyeicosatetraenoic acid, DHET Dihydroxyeicosatrienoic acid, DiHETE Dihyroxyeicosatetraenoic acid, EPDPE Epoxydocosapentaenoic acid, DiHDPA Dihydroxydocosapentaenoic acid

${ }^{3}$ LA Linoleic acid, ArA Arachidonic acid, EPA Eicosapentaenoic acid, DHA Docosahexaenoic acid

${ }^{4} \operatorname{Cov} \times \operatorname{cov} \times$ trt: $P=0.05$

\section{Lamb growth}

Lamb weight produced per ewe did not differ by treatment at 30, 60, 90, or $120 \mathrm{~d}$ of age (Table 9). Unsurprisingly, type of rearing affected lamb weight produced, with ewes rearing twins producing more lamb weight than singles for all time points $(P<0.001)$.

\section{Discussion}

Despite the necessity of inflammatory signaling at parturition, a dysfunctional inflammatory response in this period has been attributed to health disorders and decreased animal productivity [1,24]. Several studies in dairy cattle have investigated NSAID administration during the periparturient period to attenuate inflammation, but to our knowledge this is the first study to apply this intervention strategy to sheep. Our 2-dose regimen of
MEL on $\mathrm{d} 1$ and 4 after lambing decreased plasma haptoglobin concentrations, and the reduction was most pronounced for ewes with greater plasma Hp concentrations prior to treatment.

Although meloxicam is a selective inhibitor of COX-2 [25], treatment strategies that target only one enzymatic oxygenation pathway typically also have unpredicted effects on the entire oxylipid network [26]. For a thorough understanding of MEL effects on plasma oxylipid concentrations, we examined differences at each of the following levels that control oxylipid biosynthesis: 1) substrate (PUFA) availability, 2) products of multiple oxygenation pathways, and 3) the degree to which intermediate metabolites were catabolized to their end products [27].

The only difference we observed for PUFA concentrations was a 4-fold increase in ArA for MEL ewes bearing

Table 7 Nonenzymatic-derived oxylipids in plasma in control ewes and ewes treated with 90 mg meloxicam on d 1 and 4 after lambing (mean \pm SEM; $\mu \mathrm{mol} / \mathrm{L}$ )

\begin{tabular}{|c|c|c|c|c|c|c|c|c|c|}
\hline \multirow[b]{2}{*}{ Oxylipid $^{2}$} & \multirow[b]{2}{*}{ Substrate $^{3}$} & \multirow[b]{2}{*}{ CON } & \multirow[b]{2}{*}{ MEL } & \multirow[b]{2}{*}{ SEM } & \multicolumn{5}{|c|}{$P$-values ${ }^{1}$} \\
\hline & & & & & $\overline{T r t}$ & Cov $\times$ trt & Lambs & Trt $\times$ lambs & Hpcov $\times$ trt \\
\hline 5-iso-PGF $2 a^{-}-\mathrm{Vl}$ & $\operatorname{ArA}$ & 0.39 & 0.45 & 0.04 & NS & - & - & - & - \\
\hline 8-iso-PGA 2 & $\operatorname{ArA}$ & 0.40 & 0.45 & 0.06 & NS & NS & NS & 0.07 & NS \\
\hline 8-iso-PGE ${ }_{2}^{4}$ & ArA & 0.70 & 0.16 & 0.12 & $<0.01$ & NS & $<0.01$ & 0.08 & NS \\
\hline 8,12-iso-PGF $2 a^{-}-V l$ & $\operatorname{ArA}$ & 0.40 & 0.42 & 0.04 & NS & NS & NS & NS & NS \\
\hline 9-HETE ${ }^{5}$ & $\operatorname{ArA}$ & 0.06 & 0.11 & 0.04 & NS & 0.04 & NS & NS & 0.03 \\
\hline 11-HETE & $\operatorname{ArA}$ & 1.07 & 1.03 & 0.12 & NS & NS & NS & NS & $<0.01$ \\
\hline
\end{tabular}

${ }^{1} \mathrm{NS}=P>0.10$

${ }^{2} P G$ Prostaglandin, HETE Hydroxyeicosatetraenoic acid

${ }^{3}$ ArA Arachidonic acid

${ }^{4}$ Haptocov: $P=0.06$

${ }^{5}$ Cov $\times$ cov: $P=0.06$ 
Table 8 Plasma concentrations of oxidized linoleic acid metabolites derived from multiple sources and ratios of select upstream:downstream metabolites in control ewes and ewes treated with $90 \mathrm{mg}$ meloxicam on $\mathrm{d} 1$ and 4 after lambing (mean \pm SEM; $\mu \mathrm{mol} / \mathrm{L}$ )

\begin{tabular}{|c|c|c|c|c|c|c|c|c|}
\hline \multirow[b]{2}{*}{ Oxylipid or Ratio ${ }^{2}$} & \multirow[b]{2}{*}{ CON } & \multirow[b]{2}{*}{ MEL } & \multirow[b]{2}{*}{ SEM } & \multicolumn{5}{|c|}{$P$-values ${ }^{1}$} \\
\hline & & & & $\overline{T r t}$ & Cov & $\operatorname{Cov} \times$ trt & Lambs & $\begin{array}{l}\text { Hpcov } \\
\times \text { trt }\end{array}$ \\
\hline 9-HODE & 52.5 & 44.9 & 4.2 & NS & 0.01 & 0.07 & 0.03 & $<0.01$ \\
\hline 9-oxoODE & 13.99 & 12.37 & 1.24 & NS & NS & NS & 0.01 & 0.02 \\
\hline 13-HODE & 133.0 & 124.8 & 8.45 & NS & NS & $<0.01$ & NS & NS \\
\hline 13-oxoODE & 1.90 & 2.55 & 0.31 & NS & NS & NS & NS & NS \\
\hline 9-HODE:9-OXOODE ${ }^{3}$ & 3.35 & 3.59 & 0.17 & NS & NS & 0.06 & 0.06 & $<0.10$ \\
\hline 13-HODE:13-OxOODE ${ }^{4}$ & 62.3 & 51.1 & 5.4 & NS & NS & 0.04 & NS & NS \\
\hline $\begin{array}{l}\text { 9,10-EpOME:9,10- } \\
\text { DiHOME }\end{array}$ & 0.37 & 0.46 & 0.03 & 0.06 & - & - & - & - \\
\hline \multicolumn{9}{|c|}{$\begin{array}{l}{ }^{1} \mathrm{NS}=P>0.10 \\
{ }^{2} \mathrm{HODE} \text { Hydroxyoctadecadienoic acid, oxoODE Oxooctadecadien } \\
\text { Epoxyoctadecenoic acid, DiHOME Dihydroxyoctadecenoic acid } \\
{ }^{3} \mathrm{Cov} \times \operatorname{cov} \times \text { trt: } P=0.06 \\
{ }^{4} \mathrm{Cov} \times \operatorname{cov}: P=0.09 ; \text { Cov } \times \operatorname{cov} \times \operatorname{trt:} P=0.04\end{array}$} \\
\hline
\end{tabular}

singletons. Although PUFA can be oxidized by each pathway, some pathways have a substrate preference [26]. In the case of COX-2, ArA is preferentially oxidized. Given MEL's inhibition of COX-2, it is seemingly logical for the substrate to accumulate; however, ArA oxidation is expected to shift to other pathways in this scenario [25]. Additionally, it is unclear why MEL treatment decreased, rather than increased, ArA concentration in ewes with greater initial $\mathrm{Hp}$ concentrations. Because this result is somewhat counterintuitive, additional studies are needed to replicate the finding and explore potential explanations.

Direct downstream effects of COX inhibition were observed through the overall reduction in $\mathrm{PGF}_{2 \alpha}$ and decreased HHTrE in MEL ewes with greater pretreatment inflammation. As all COX-derived oxylipids detected in this study were metabolites of ArA, the observed effect for HHTrE could be partially attributed to reduced substrate availability. Effects on $\mathrm{PGF}_{2 \alpha}$ but not other prostanoids $\left(\mathrm{PGD}_{2}, \mathrm{PGE}_{2}, \mathrm{PGI}_{2}\right)$ generated from the same substrate (PGH) could be due to the timing of our

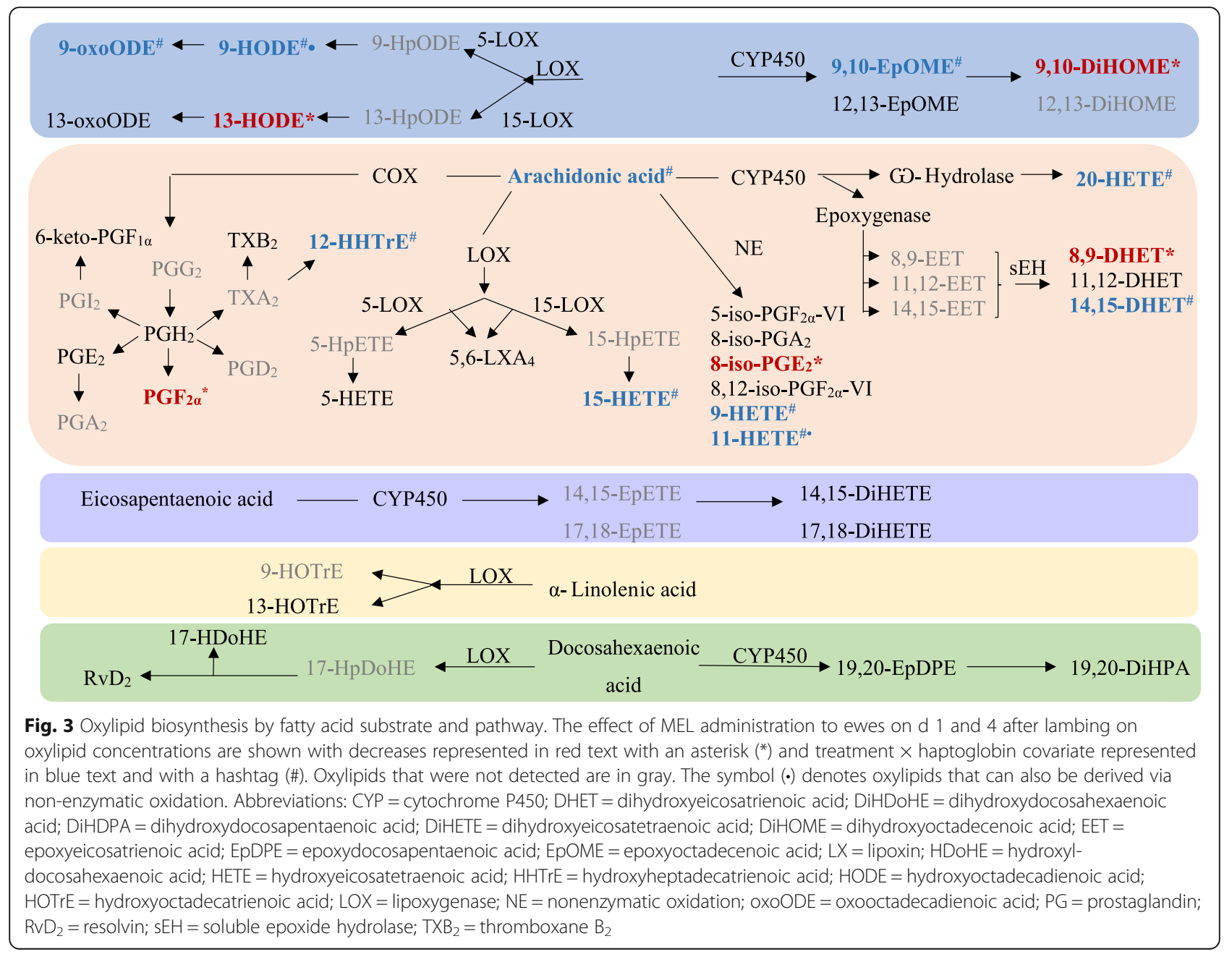



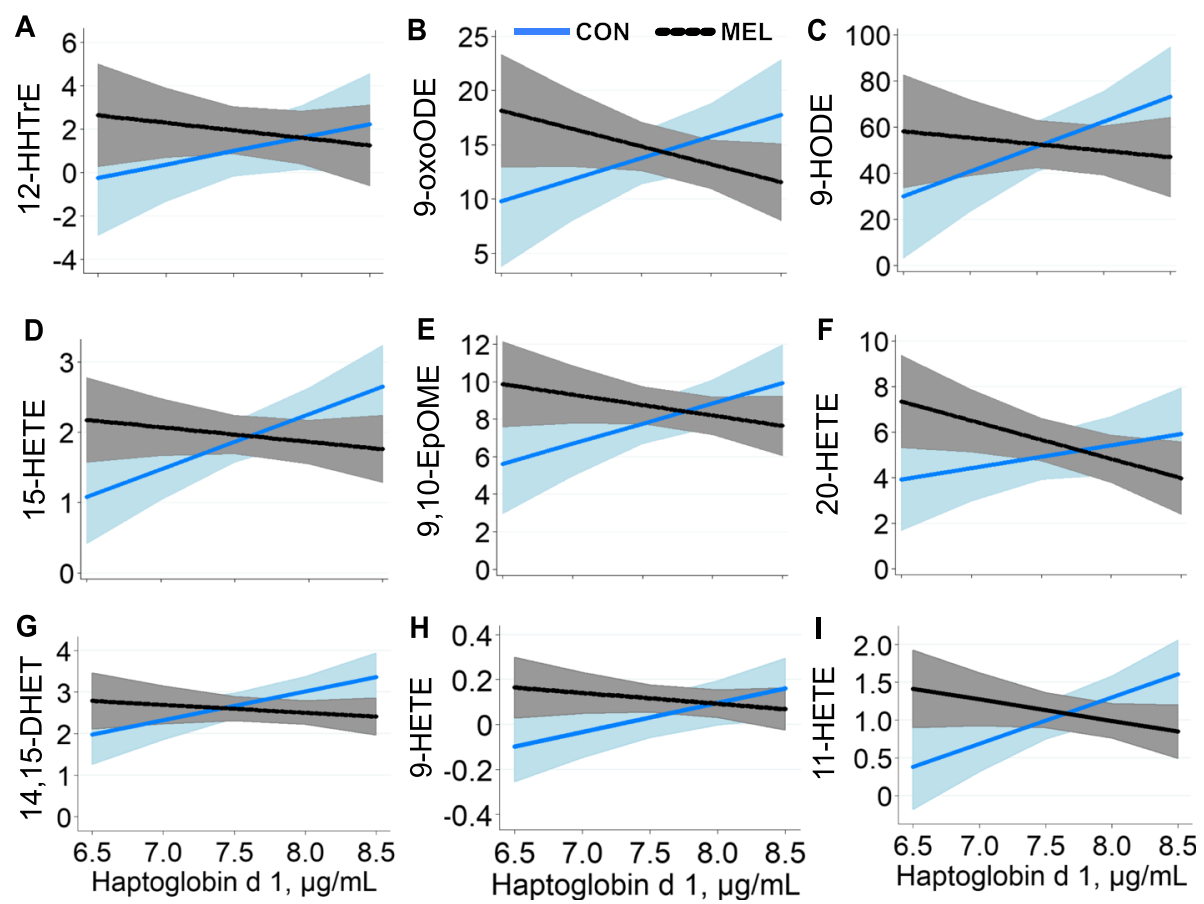

Fig. 4 Meloxicam alters plasma oxylipid relationships with baseline haptoglobin. Treatment (trt) $\times$ haptoglobin covariate (log; loghaptocov) interactions for oxylipid concentrations ( $\mu \mathrm{mol} / \mathrm{L}$ ) in control ewes (CON; blue line) and ewes treated with $90 \mathrm{mg}$ meloxicam (MEL; black line) on d 1 and 4 after lambing. All interactions $P<0.05$; shaded areas represent 95\% confidence intervals. Cyclooxygenase-derived oxylipid: a 12-HHTrE. Lipoxygenase-derived oxylipids: b 9-oxoODE, c 9-HODE, d 15-HETE. Cytochrome P450-derived oxylipids: e 9,10-EpOME, f 20-HETE, g 14,15-DHET. Nonenzymatically derived oxylipids: $\mathbf{h}$ 9-HETE, i 11-HETE

sample relative to the stage of inflammation [28]. For example, $\mathrm{PGE}_{2}$ is elevated during the early stages of inflammation compared with $\mathrm{PGD}_{2}$ which is more prevalent during the final stages of the response [29].

Meloxicam effects extended to oxylipids derived from the other oxygenation pathways, with the effects largely related to alterations in redox state and inflammatory status. As isoprostanes are only produced when there is a significant shift in redox state [24], they are considered the gold standard biomarkers of oxidative stress [30]. Thus, the observed decrease in 8 -iso- $\mathrm{PGE}_{2}$ is one indicator that MEL reduced oxidative stress.

Oxylipids formed by NE oxidation also serve as indicators of oxidative stress and include 9-HETE, 11-HETE, and 9-HODE. Both 9-HETE and 11-HETE were decreased in MEL ewes with greater degrees of initial inflammation, suggesting a possible improved redox status. As both are predominately derived by NE oxidation of ArA, reduced substrate availability could partially explain the reductions in 9- and 11-HETE. Kuhn et al. [31] reported a similar scenario in which milk concentration of 11-HETE was elevated in early lactation; however, the significant correlation with its substrate ArA in milk $(r=0.60)$ only partially explained the elevation in their study. The greater oxidative environment of the mammary gland also contributed. Since the LA-derived
9-HODE can be produced both enzymatically via LOX or through NE oxidation, it can also serve as a marker of oxidative status [31]. Similar to 9 and 11-HETE, 9HODE concentration was less in MEL ewes with greater degrees of initial inflammation, but since LA concentration was not different with MEL, this result can be more confidently attributed to the presence of fewer oxidants. Such a claim would be even further supported had we measured racemic structures of 9-HODE and could show that it was the proportion formed by NE that was reduced by MEL.

Decreased concentrations of oxylipids that contribute to a prooxidant environment would also indicate improved oxidative status. 20-HETE is a CYP-derived oxylipid that is not only a prooxidant itself, but also indirectly exacerbates oxidative stress via stimulation of mitochondrial reactive oxygen species production and activation of NADPH oxidase enzymes [32, 33]. Meloxicam decreased 20-HETE concentration in ewes with greater initial inflammation, which suggests decreased presence of reactive metabolites and thus improved redox status.

The initial products from 15-LOX oxidation of ArA and LA (15-HPETE and 13-HPODE, respectively) are also highly reactive and greatly contribute to oxidative stress [34]. Prior to LC-MS quantification, 15-HPETE and 13-HPODE had to be reduced to their hydroxyl and 


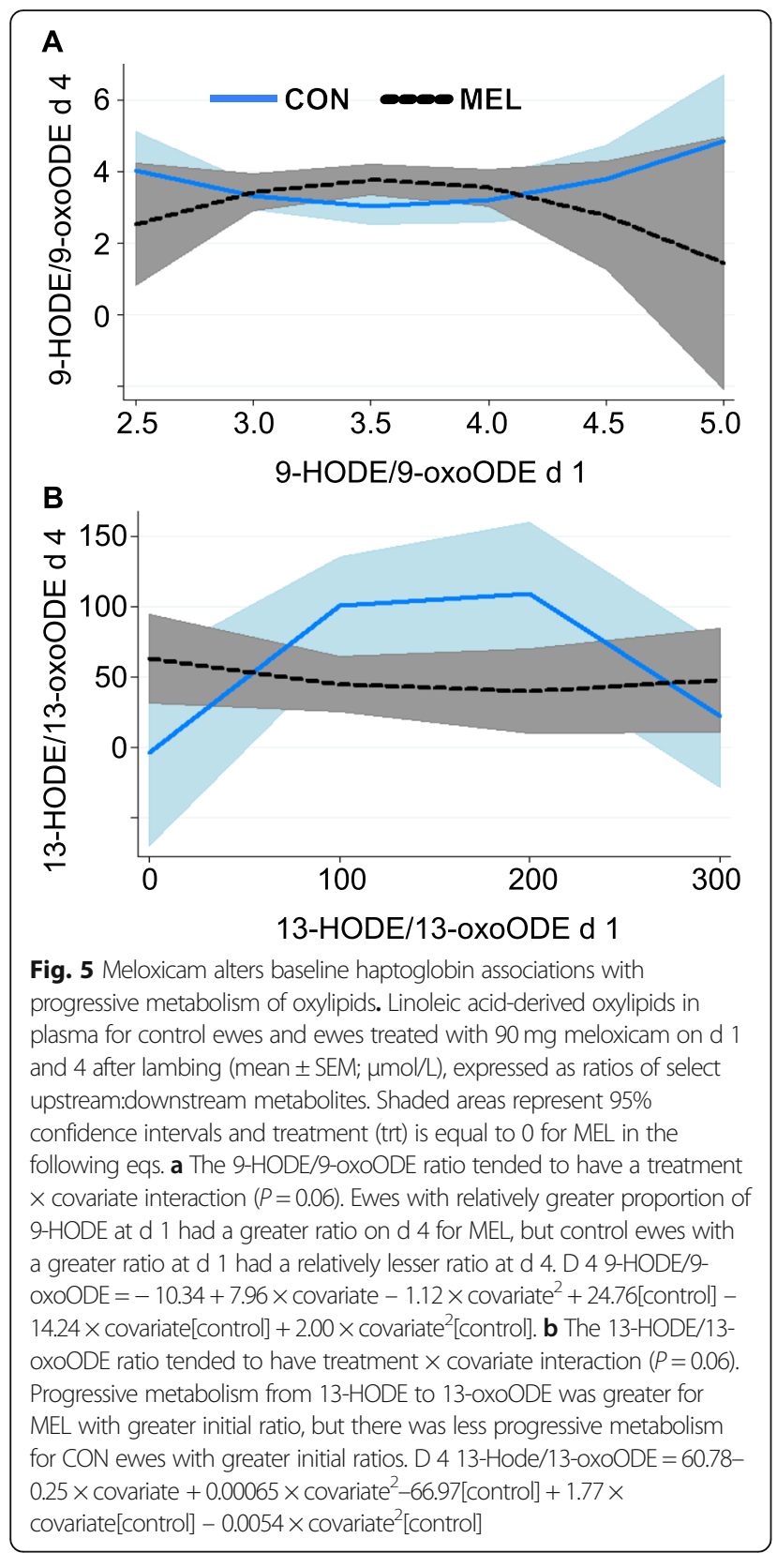

hydroperoxy derivatives. Thus, values for 15-HETE and 13-HODE represent the combined concentrations of the hydroperoxides and their hydroxyl derivatives. Treatment with MEL decreased concentration of 15-HETE in ewes with greater initial inflammation. Although relative contributions of 15-HPETE and 15-HETE cannot be teased apart in our data, our observed decrease in 15HETE could have been driven by reductions in 15HPETE. This alteration would further support improved oxidative status through decreased reactive metabolite availability.

The progressive metabolism of LA-derived oxylipids through the LOX pathway was also shifted. The ratios of
13-HODE:13-oxoODE and 9-HODE:9-oxoODE indicated further metabolism of 13-HODE to 13-oxoODE and less oxidation of 9-HODE to 9-oxoODE for MEL ewes compared to control. The further progression to 13-oxoODE is favorable because of its anti-inflammatory properties as a PPAR gamma ligand [35].

Soluble epoxide hydrolase (sEH), the enzyme that catalyzes the further metabolism of EETs to DHETs and EpHOMEs to DiHOMEs, is upregulated by prooxidant status [36]. Evaluation of ratios between these oxylipids and their downstream metabolites can provide some insight into $\mathrm{SEH}$ activity. The tendency for MEL to increase 9,10-EpOME/9,10-DiHOME could be the result of decreased sEH activity because of improved redox status. As DiHOME are more toxic than EpOME [37], the greater ratio in MEL ewes is preferable. Ratios of metabolites from CYP oxidation, EETs to DHETs, could not be evaluated. Although detected in some samples, EET concentrations were not statistically analyzed due to low concentrations with little variability. MEL did decrease 8,9-DHET overall and decreased 12,15-DHET in ewes with greater initial inflammation. Again, these reductions could indicate decreased sEH activity, but without knowing concentrations of their substrate precursors, we cannot differentiate between MEL shifting whole pathway flux vs. progression of oxidation within a pathway.

Oxylipids largely regulate inflammation by influencing the development of oxidative stress [24]. Our data reveal improved oxidant status for ewes treated with MEL, especially for those with greater initial degrees of inflammation. The haptoglobin covariate $\times$ treatment interaction was significant for 9 oxylipids with an additional 2 tending to be significant. The interaction for each of these were in the same direction: decreased oxylipid concentrations for MEL ewes with greater inflammation that were otherwise increased for control ewes. The fact that characteristically pro- and anti-inflammatory oxylipids were both altered in a similar manner demonstrates the natural balance within the complex oxylipid network. Not only does it seem oxylipids balance each other, but individual oxylipids can have different effects based on the receptor present on target cells or stage of inflammation. For example, 8-iso$\mathrm{PGE}_{2}$ promotes vasoconstriction when working through the thromboxane receptor, but vasodilation through the $\mathrm{PGE}_{2}$ prostanoid receptor [38]. Overall, our results demonstrate MEL decreased systemic inflammation in ewes with greater degrees of initial inflammation, in part because of alterations to oxylipid biosynthesis across multiple oxidation pathways.

The many interactions we observed with initial inflammatory status could be a possible explanation to the inconsistency of NSAID response in transition dairy cattle studies. For example, Carpenter et al. [7] reported substantial whole-lactation milk yield responses after oral 
Table 9 Weight of lamb produced per ewe (kg) at approximately 30, 60, 90, and $120 \mathrm{~d}$ after lambing for control ewes and ewes treated with $90 \mathrm{mg}$ meloxicam on d 1 and 4 after lambing. To obtain average weight of an individual lamb at any time point, divide stated value by 1.58 (the average number of lambs reared per ewe) and add $6.3 \mathrm{~kg}$ (average birth weight)

\begin{tabular}{|c|c|c|c|c|c|}
\hline \multirow[b]{2}{*}{ Age, $d$} & \multirow[b]{2}{*}{$\mathrm{CON}$} & \multirow[b]{2}{*}{ MEL } & \multirow[b]{2}{*}{ SEM } & \multicolumn{2}{|c|}{$P$-values } \\
\hline & & & & $\overline{T r t}$ & $\mathrm{TOR}^{2}$ \\
\hline 30 & 14.9 & 15.6 & 0.6 & NS & $<0.001$ \\
\hline 60 & 35.3 & 36.1 & 1.3 & NS & $<0.001$ \\
\hline 90 & 55.0 & 55.7 & 1.7 & NS & $<0.001$ \\
\hline 120 & 72.1 & 75.9 & 2.2 & NS & $<0.001$ \\
\hline
\end{tabular}

${ }^{\top} \mathrm{NS}=P>0.10$

${ }^{2}$ TOR Type of rearing (single, twin). TOR $\times$ trt was tested but not significant

administration of sodium salicylate to dairy cows for $3 \mathrm{~d}$ after calving; however, when the study was later replicated, no difference in milk production through $120 \mathrm{~d}$ was observed [39]. As plasma haptoglobin concentrations were nearly 3 -fold greater in the former cohort $(\sim$ 600 vs. $200 \mu \mathrm{g} / \mathrm{mL}$ ), authors speculated a milk response to NSAID treatment could be dependent on baseline inflammation [39]. As discussed throughout the paper, our data supports the notion that response to postpartum NSAID treatment in ruminants is dependent on initial inflammatory status.

Despite MEL decreasing inflammation, no treatment effect was observed for milk G6P, an indirect indicator of energy balance. Zachut and others [20] have demonstrated a negative linear correlation between milk G6P concentration and energy balance $(r=-0.45)$. As systemic inflammation is correlated with decreased feed intake, we hypothesized alleviation of inflammation would promote feed intake and greater energy balance. Feed intake and milk yield data were not available, therefore analysis of milk G6P was employed to gain some insight into energy balance. To our knowledge, this is the first experiment to report milk G6P concentrations in sheep milk; values for controls were only slightly lower than concentrations reported for dairy cattle on d 3 of lactation $(200-350 \mu \mathrm{mol} / \mathrm{L}[40])$.

Postpartum meloxicam treatment of ewes did not affect lamb weight produced per ewe (a proxy of lamb growth); however, our small sample size likely limited our ability to detect a statistical difference. It is also possible that a greater dose of MEL (e.g. $2 \mathrm{mg} / \mathrm{kg} \mathrm{BW}$ ) may have yielded differences in milk yield and growth of suckling lambs, although a recent study [9] could argue against the potential benefit of a greater dose. Future studies should reevaluate the hypothesis that postpartum MEL might increase ewe milk production and thereby increase lamb growth, especially in ewes bearing multiple offspring. Even though ewes suckling twin lambs produce $17-61 \%$ more milk than ewes suckling single lambs [41], the nutrient supply is split between the 2 lambs, resulting in $60-80 \%$ of the nutrients $(20-40 \%$ less compared to a singleton). Increasing nutrient supply via increased milk production could increase pre-weaning lamb growth, thereby increasing profit potential for sheep producers.

\section{Conclusions}

Postpartum meloxicam administration decreased ewe inflammatory status as measured by plasma haptoglobin, with reductions greatest for those with greater initial haptoglobin concentrations. MEL increased plasma ArA concentrations in ewes bearing singletons, but decreased ArA in ewes with greater initial inflammation. Meloxicam also decreased plasma concentrations of an array of oxylipids extending across different PUFA substrates and oxidation pathways, and altered their progressive metabolism. Many of the oxylipid MEL effects pointed to improved redox state that paralleled the reductions in inflammation. No differences in lamb growth were detected, but future research with a larger sample size, particularly of twins and triplets, is warranted.

\section{Abbreviations}

ArA: Arachidonic acid; COX: Cyclooxygenase; CYP: Cytochrome P450;

DiHDoHE: Dihydroxydocosahexaenoic acid;

DiHDPA: Dihydroxydocosapentaenoic acid;

DiHETE: Dihydroxyeicosatetraenoic acid; DiHOME: Dihydroxyoctadecenoic acid; DHET: Dihydroxyeicosatrienoic acid; EET: Epoxy-eicosatrienoic acid; EpDPE: Epoxydocosapentaenoic acid; EpOME: Epoxyoctadecenoic acid; FA: Fatty acid; G6P: Glucose-6-phosphate; HDoHE: Hydroxyl-docosahexaenoic acid; HETE: Hydroxyeicosatetraenoic acid; HHTrE: Hydroxyeicosatrienoic acid; HODE: Hydroxyoctadecadienoic acid; HOTrE: Hydroxyocctadecatrienoic acid; Hp: Haptoglobin; LnA: Linoleic acid; LOX: Lipoxygenase; LXA MEL: Meloxicam; NE: Nonenzymatic oxidation; OxoODE: Oxooctadecadienoic acid; PG: Prostaglandin; PUFA: Polyunsaturated fatty acid; $\mathrm{RvD}_{2}$ : Resolvin;

SEH: Soluble epoxide hydrolase; TEAC: Trolox equivalent antioxidant capacity; $\mathrm{TXB}_{2}$ : Thromboxane $\mathrm{B}_{2}$

\section{Acknowledgements}

Authors would like to thank the undergraduate student employees at lowa State University Sheep Teaching Farm that assisted with biological sample collections and recording of lamb weights.

\section{Authors' contributions}

$\mathrm{KO}$ participated in initial study design, analyzed plasma samples for $\mathrm{Hp}$ concentration and TEAC and milk samples for glucose and glucose-6phosphate concentrations. KO compiled and performed statistical analysis on all data, and drafted the manuscript. BB participated in study design, oversight of statistical analysis, and manuscript revision. LS was responsible for 
plasma FA and oxylipid methodology. JG analyzed plasma samples for fatty acid and oxylipid concentrations. LM analyzed plasma samples for Hp concentrations. TS assisted with statistical analysis and results interpretation. TJ, EP and CS were responsible for sample collection and processing. CY participated in initial study design, obtained research funding, supervised the trial, and was responsible for provision of milk and plasma samples. All authors reviewed and approved the final manuscript.

\section{Funding}

This research was funded by a Let's Grow grant through the American Sheep Industry.

\section{Availability of data and materials}

The datasets used and/or analyzed during this study are available from the corresponding author on reasonable request.

\section{Ethics approval and consent to participate}

All animal procedures were reviewed and approved by the lowa State University Committee on Animal Care.

\section{Consent for publication}

All authors provide their consent to this publication.

\section{Competing interests}

The authors declare that they have no competing interests.

\section{Author details}

'Department of Animal Sciences and Industry, Kansas State University, Manhattan 66506, USA. ${ }^{2}$ College of Veterinary Medicine, Michigan State University, 2265K Anthony Hall, East Lansing, Ml 48824-1225, USA.

${ }^{3}$ Department of Animal Science, lowa State University, Ames, IA, USA.

Received: 8 February 2020 Accepted: 17 May 2020

Published online: 01 July 2020

\section{References}

1. Bradford BJ, Yuan K, Farney JK, Mamedova LK, Carpenter AJ. Inflammation during the transition to lactation: new adventures with an old flame. J Dairy Sci. 2015;98:6631-50. https://doi.org/10.3168/jds.2015-9683.

2. Bertoni $\mathrm{G}$, Trevisi $\mathrm{E}$, $\operatorname{Han} \mathrm{X}$, Bionaz M. Effects of inflammatory conditions on liver activity in puerperium period and consequences for performance in dairy cows. J Dairy Sci. 2008;91:3300-10. https://doi.org/10.3168/jds.2008-0995.

3. Nightingale CR, Sellers MD, Ballou MA. Elevated plasma haptoglobin concentrations following parturition are associated with elevated leukocyte responses and decreased subsequent reproductive efficiency in multiparous Holstein dairy cows. Vet Immunol Immunopathol. 2015;164:16-23. https:// doi.org/10.1016/j.vetimm.2014.12.016.

4. Huzzey JM, Mann S, Nydam DV, Grant RJ, Overton TR. Associations of peripartum markers of stress and inflammation with milk yield and reproductive performance in Holstein dairy cows. Prev Vet Med. 2015;120: 291-7. https://doi.org/10.1016/.prevetmed.2015.04.011.

5. Shock DA, Renaud DL, Roche SM, Poliquin R, Olson ME. Evaluating the impact of meloxicam oral suspension administered at parturition on subsequent production, health, and culling in dairy cows: a randomized clinical field trial. PLoS One. 2018;13:1-13.

6. Swartz TH, Schramm HH, Bewley JM, Wood CM, Leslie KE. Meloxicam administration either prior to or after parturition: effects on behavior, health, and production in dairy cows. J Dairy Sci. 2018;101:10151-67. https://doi. org/10.3168/jds.2018-14657.

7. Carpenter AJ, Ylioja CM, Vargas CF, Mamedova LK, Mendonça LG, Coetzee $\mathrm{JF}$, et al. Hot topic: early postpartum treatment of commercial dairy cows with nonsteroidal antiinflammatory drugs increases whole-lactation milk yield. J Dairy Sci. 2016;99:672-9.

8. Sheldon IM, Noakes DE, Bayliss M, Dobson $\mathrm{H}$. The effect of oestradiol on postpartum uterine involution in sheep. Anim R. 2003;78:57-70.

9. Colditz IG, Paull DR, Lloyd JB, Johnston L, Small AH. Efficacy of meloxicam in a pain model in sheep. Aust Vet J. 2019;97:23-32.

10. Small AH, Belson S, Holm M, Colditz IG. Efficacy of a buccal meloxicam formulation for pain relief in merino lambs undergoing knife castration and tail docking in a randomised field trial. Aust Vet J. 2014;92:381-8.
11. Paull DR, Lee C, Atkinson SJ, Fisher AD. Effects of meloxicam or tolfenamic acid administration on the pain and stress responses of merino lambs to mulesing. Aust Vet J. 2008:86:303-11.

12. Steinmeyer J. Pharmacological basis for the therapy of pain and inflammation with nonsteroidal anti-inflammatory drugs. Arthritis Res. 2000;2:379-85.

13. Mainau E, Cuevas A, Ruiz-de-la-torre JL, Abbeloos E, Manteca X. Effect of meloxicam administration after calving on milk production, acute phase proteins, and behavior in dairy cows. J Vet Behav Clin Appl Res. 2014;9:35763. https://doi.org/10.1016/j.jveb.2014.07.007.

14. Newby NC, Leslie KE, Dingwell HDP, Kelton DF, Weary DM, Neuder L, et al. The effects of periparturient administration of flunixin meglumine on the health and production of dairy cattle. J Dairy Sci. 2017;100:582-7. https:// doi.org/10.3168/jds.2016-11747.

15. de Grauw JC, van de Lest CHA, van Weeren PR. A targeted lipidomics approach to the study of eicosanoid release in synovial joints. Arthritis Res Ther. 2011;13:R123.

16. Valdes AM, Ravipati S, Pousinis P, Menni C, Mangino M, Abhishek A, et al. Omega-6 oxylipins generated by soluble epoxide hydrolase are associated with knee osteoarthritis. J Lipid Res. 2018;59:1763-70.

17. Shukla M, Singh G, Sindhura BG, Telang AG, Rao GS, Malik JK. Comparative plasma pharmacokinetics of meloxicam in sheep and goats following intravenous administration. Comp Biochem Physiol. 2007;145:528-32.

18. Stock ML, Johann F, Kukanich B, Smith BI. Pharmacokinetics of intravenously and orally administered meloxicam in sheep. Am J Vet Res. 2013;74:779-83.

19. Silanikove N, Merin U, Shapiro F, Leitner G. Milk metabolites as indicators of mammary gland functions and milk quality. J Dairy Res. 2014;81:358-63.

20. Zachut M, Kra G, Portnik Y, Shapiro F, Silanikove N. Milk glucose-6phosphate dehydrogenase activity and glucose-6-phosphate are associated with oxidative stress and serve as indicators of energy balance in dairy cows. RSC Adv. 2016;6:65412-7. https://doi.org/10.1039/ C6RA11924G.

21. Cooke RF, Arthington JD. Concentrations of haptoglobin in bovine plasma determined by ELISA or a colorimetric method based on peroxidase activity. J Anim Physiol Anim Nutr (Berl). 2013:97:531-6.

22. Putman AK, Brown JL, Gandy JC, Abuelo A, Sordillo LM. Oxylipid profiles of dairy cattle vary throughout the transition into early mammary gland involution. J Dairy Sci. 2019;102:2481-91 https://linkinghub.elsevier.com/ retrieve/pii/S0022030219300773.

23. Mavangira V, Gandy JC, Zhang C, Ryman VE, Jones AD, Sordillo LM. Polyunsaturated fatty acids influence differential biosynthesis of oxylipids and other lipid mediators during bovine coliform mastitis. J Dairy Sci. 2015; 98:6202-15. https://doi.org/10.3168/jds.2015-9570.

24. Mavangira V, Sordillo LM. Role of lipid mediators in the regulation of oxidative stress and inflammatory responses in dairy cattle. Res Vet Sci. 2018;116:4-14. https://doi.org/10.1016/j.rvsc.2017.08.002.

25. Dennis EA, Norris PC. Eicosanoid storm in infection and inflammation. Nat Rev Immunol. 2015;15:511-23. https://doi.org/10.1038/nri3859.

26. Sordillo LM. Symposium review: Oxylipids and the regulation of bovine mammary inflammatory responses 1. J Dairy Sci. 2018;101:5629-41. https:// doi.org/10.3168/jds.2017-13855.

27. Willenberg I, Ostermann Al, Schebb NH. Targeted metabolomics of the arachidonic acid cascade: current state and challenges of LC-MS analysis of oxylipins. Anal Bioanal Chem. 2015:407:2675-83.

28. Tilley SL, Coffman TM, Koller BH. Mixed messages: modulation of inflammation and immune responses by prostaglandins and thromboxanes. J Clin Invest. 2001;108:15-23.

29. Gilroy DW, Colville-Nash PR, Willis D, Chivers J, Paul-Clark MJ, Willoughby DA. Inducible cyclooxygenase may have anti-inflammatory properties. Nat Med. 1999:5:698-701.

30. Kuhn MJ, Mavangira V, Gandy JC, Sordillo LM. Production of 15-F2t-isoprostane as an assessment of oxidative stress in dairy cows at different stages of lactation. J Dairy Sci. 2018;101:9287-95. https://doi.org/10.3168/jds.2018-14669.

31. Kuhn M, Mavangira V, Gandy JC, Sordillo LM. Differences in the oxylipid profiles of bovine milk and plasma at different stages of lactation. J Agric Food Chem. 2017;65:4980-8.

32. Han Y, Zhao H, Tang H, Li X, Tan J, Zeng Q, et al. 20Hydroxyeicosatetraenoic acid mediates isolated heart ischemia/reperfusion injury by increasing NADPH oxidase-derived reactive oxygen species production. Circ J. 2013;77:1807-16.

33. Waldman M, Peterson SJ, Arad M, Hochhauser E. The role of 20-HETE in cardiovascular diseases and its risk factors. Prostaglandins Other Lipid 
Mediat. 2016;125:108-17. https://doi.org/10.1016/j.prostaglandins.2016.05. 007.

34. Mattmiller SA, Carlson BA, Sordillo LM. Regulation of inflammation by selenium and selenoproteins: impact on eicosanoid biosynthesis. J Nutr Sci. 2013;2:1-13.

35. Altmann R, Hausmann M, Spo T, Gruber M, Bull AW, Menzel K, et al. 13-OxoODE is an endogenous ligand for PPARg in human colonic epithelial cells. Biochem Pharmacol. 2007;74:612-22.

36. Abdelhamid G, El-kadi AOS. Buthionine sulfoximine, an inhibitor of glutathione biosynthesis, induces expression of soluble epoxide hydrolase and markers of cellular hypertrophy in a rat cardiomyoblast cell line: roles of the NF-KB and MAPK signaling pathways. Free Radic Biol Med. 2015;82:1-12. https://doi.org/10.1016/.jfreeradbiomed.2015.01.005.

37. Slim R, Hammock B, Toborek M, Robertson LW, NJ W, CHP M, et al. The role of methyl-linoleic acid epoxide and diol metabolites in the amplified toxicity of linoleic acid and polychlorinated biphenyls to vascular endothelial cells. Toxicol Appl Pharmacol. 2001;171:184-93.

38. Milne $\mathrm{GL}$, Dai Q, Roberts $\amalg$. The isoprostanes -25 years later. Biochim Biophys Acta. 1851;2015:433-45. https://doi.org/10.1016/.jbbalip.2014.10.007.

39. Carpenter AJ, Ylioja CM, Mamedova LK, Olagaray KE, Bradford BJ. Effects of early postpartum sodium salicylate treatment on long-term milk, intake, and blood parameters of dairy cows. J Dairy Sci. 2018;101:1437-47. https://doi. org/10.3168/jds.2017-13057.

40. Olagaray KE, Brouk MJ, Mamedova LK, Sivinski SE, Liu H, Robert F, et al. Dietary supplementation of Scutellaria baicalensis extract during early lactation decreases milk somatic cells and increases whole lactation milk yield in dairy cattle. PLoS One. 2019;14:e0210744.

41. Cardellino RA, Benson ME. Lactation curves of commercial ewes rearing lambs. J Anim Sci. 2002;80:23-7.

Ready to submit your research? Choose BMC and benefit from:

- fast, convenient online submission

- thorough peer review by experienced researchers in your field

- rapid publication on acceptance

- support for research data, including large and complex data types

- gold Open Access which fosters wider collaboration and increased citations

- maximum visibility for your research: over $100 \mathrm{M}$ website views per year

At $\mathrm{BMC}$, research is always in progress.

Learn more biomedcentral.com/submissions 